\title{
CHALLENGES ON URBAN AGEING IN HIGH DENSITY SETTLEMENTS: Relationship of built-environment attributes and lifestyle of elderly in Western province, Sri Lanka
}

\author{
JAYARATNE N.N. ${ }^{1} \&$ RAJAPAKSHA I. ${ }^{1}$ \\ 1,2University of Moratuwa, Moratuwa, Sri Lanka \\ ${ }^{1}$ nethmijayaratne@gmail.com
}

\begin{abstract}
Urbanization and population aging are two key phenomena in the twenty-first century that concerns the elders living in cities, especially those in low- and middle-income countries like Sri Lanka. In such a setting, understanding the responsiveness of the built environment for active aging is crucial. However, even the few available studies are prioritized on health rather than the built environment attributes. Therefore, this study aims to assess the built environment attributes related to elders, for the first time, in developing countries like Sri Lanka. The assessment method composes of two case studies in Colombo, Sri Lanka with a questionnaire survey, an axial map, and a frequency analysis using the SPSS software. The case studies comprise of a middle-income and a low-income settlement both with high population density. The analysis results explicitly informed that, in comparison, the middle-income settlement is more adversely affected by the built environment response related to health and social relationships. This finding is further supported by the prominence in health-related issues of loneliness ( $\rho$-value .042) and lack of freedom ( $\rho$-value .014 ) in the middle-income settlement. The built environment attributes were ranked based on their significance in correlation with the Quality-of-Life measures and the individual age-related characteristics. This was further developed for an appraisal that assesses health-related aspects of built environment response for vulnerable age groups like elders. The findings and the appraisal could support the future decision-making process of the National health budget and future urban design interventions since Sri Lanka has the highest South Asian aging population.
\end{abstract}

Keywords: Urbanization, Population Ageing, Quality of Life, Active Ageing, Built Environment response

\section{Introduction}

Population aging is considered a major demographic concern of the twenty-first century specified as the relative increase of elders in the population. It concerns the increasing number of elders compared to the birth rate of a country where for demographic purposes the aging population is considered to be 60 years or older according to Asian Development Bank (Asian Development Bank, 2019). At present one in every nine persons globally is of age 60 years or over and it is predicted to be one in every five by 2050 , a phenomenon that no longer can be ignored. Furthermore, the projected data implies that the elderly will surpass the minors' population for the first time in 2047. As informed in Urban and Rural Population by Age and Sex (URPAS,2014), cities are currently home to more than 500 million of age 65 and older. One could argue whether cities are the ideal place to age with the physical, social, and economic barriers that challenge the aspect of active aging. In such a setting, understanding the responsiveness of built environment attributes for active aging is an important pillar of research.

Synergistically, it was highlighted that with the majority of the global population (fifty-four percent projected to be sixty-six percent by 2050 (UN Habitat, 2014)) residing in cities, 80\% of the global aged population will be in low-middle income countries by 2050 (HelpAge International, 2015). Thus, making it challenging for cities in South Asian countries like Sri Lanka with rapidly aging populations and the majority living in urbanizing areas to adapt. 
Therefore, though there are generic studies on urban aging, and a few developed specifically for elders living in cities, most have been based on developed rather than developing countries. Even the available studies on developing South Asian countries focus on the health-related aspect rather than the effect of the built environment for active aging in urban areas. Thus, there is a significant research gap in assessment on population aging in cities in developing South Asian countries like Sri Lanka.

\subsection{URBAN AGEING AND AGE-FRIENDLY CITIES}

South Asian cities are challenged due to the unbearable degrees of air pollution, low level of activity, and poor nourishment heading to epidemics of Non-Communal Diseases (NCDs). Tönnies (1957) explains that loneliness, a measure observed in both the urban and rural contexts of elderly population affects more in urban areas as rural settings fosters more social integration.

The cities are at high risk of untimely disasters together with the low resilience and being overlooked in times of emergencies makes the older population a more vulnerable group. Furthermore, the fear of crime and lack of social links can intensify their vulnerability. Therefore, the need to create inclusive cities is crucial which is also established in the SDGs from the World Humanitarian Summit and the New Urban Agenda from Habitat III.

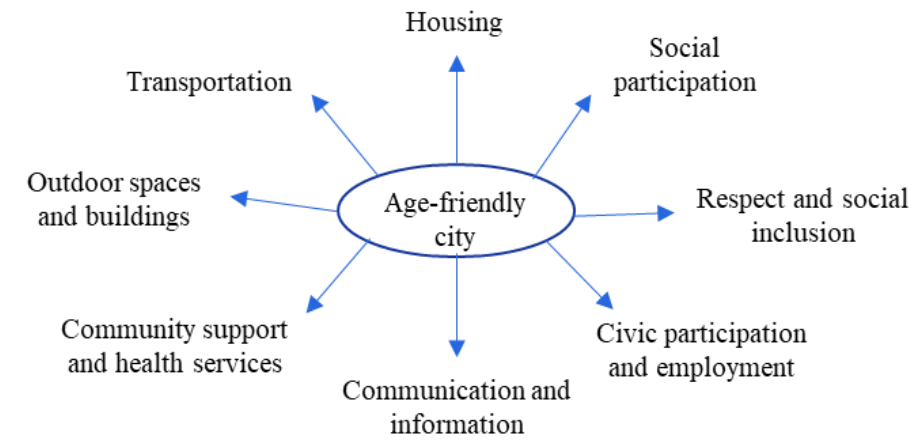

Figure 12 Age-friendly city key domains Source: $W H O$ (2007)

An "age-friendly" model for urban areas focusing on the domains in Figure 1 was initiated by the WHO (2005). It is perceived as an age-friendly city by WHO (2007) if it adapts it structure and services to be inclusive of elders with varying needs and capacities. WHO's framework highlights active aging as the key to increasing better health opportunities, activity, and security, for a better lifestyle of the aged (WHO, 2007:5). The research aimed at developing an appraisal to support the decision-making in designing inclusive built environments by assessing the built environment attributes that affect the well-being of elders living in urban areas of low-middle income countries like Sri Lanka.

\subsection{URBAN AGEING IN SRI LANKA}

Definition of elderly can vary while in most developing countries like Sri Lanka it is explained as the 60 years or more which is the retirement age. It is projected by 2050 that two-third of the aged population will be in developing countries with 8 out of 10 in developing areas. By 2030 the share of elders in Asia is projected to go up to 66 percent. The elderly are functionally classified as "young elderly" from 60-74 years and the "old elderly" which is 75 years and older (Youmans, 1977).

Sri Lanka being a low-middle income country it is the first of the South Asian countries to go through this demographic transition. The statistics, explain that how Sri Lanka has a greater population of elders than other South Asian countries in 2012. Though there are general policies for the needs of the aged in South Asian countries like Sri Lanka the effectiveness of the policies so far is doubtful and the aspect of lifestyle for the elderly is not much explored. In such a setting, identifying the key attributes for healthy aging is vital.

\subsection{BUILT ENVIRONMENT AND LIFESTYLE OF ELDERS IN CITIES}

The well-being of elders residing in cities for healthy aging mainly depends on the scale of the built environment they are most active around. In general, people are seen to be active around different spatial 
scales of urban built environments in varying levels such as regional and city or community (Loo et.al., 2017). The relativity of different spatial scales for elders in urban areas is shown in Figure 2.

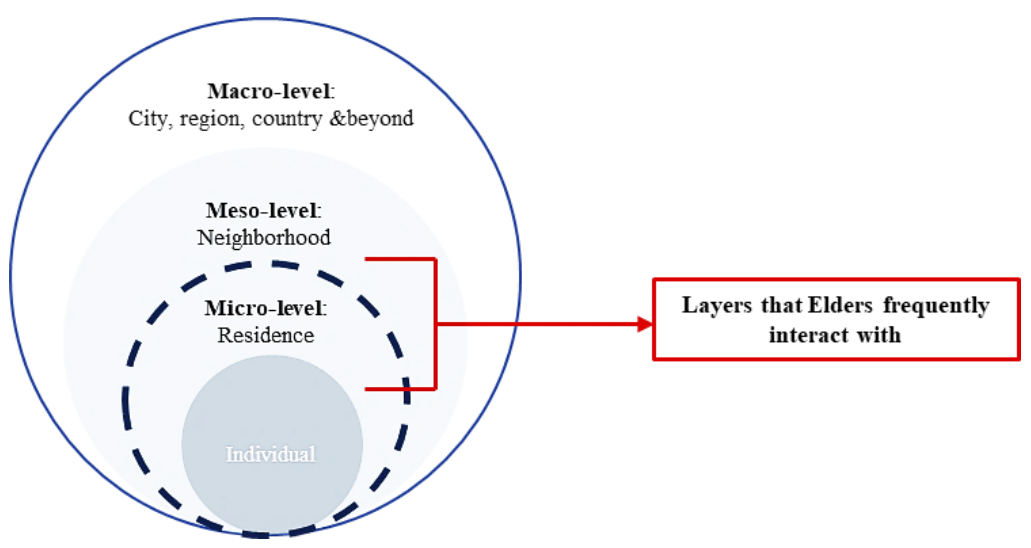

Figure 2 Different scales of living environment (Source: Loo et.al., 2017)

The micro-scale living environment illustrated implies the indoor residential environment while macro refers to the city and the neighborhood environment relates to the meso-level. However, due to the restrictions in mobility and sensory impairments, the areas of activity and movement of elders are limited (Chaudhury et al., 2016). Therefore, mostly they spend time within the meso and the micro levels of the living environment thus, the conditions of the external living environment are crucial for elders.

\begin{tabular}{|c|c|c|c|}
\hline \multirow{2}{*}{\multicolumn{2}{|c|}{ Assessment criteria }} & \multicolumn{2}{|c|}{ Evaluation criteria } \\
\hline & & Qualitative & Quantitative \\
\hline \multirow{4}{*}{ 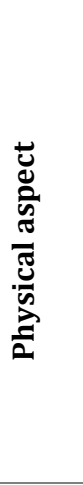 } & 1.1 Land use ratio & $\begin{array}{l}\text { Type of building functions, scale, } \\
\text { and the degree of the mix of } \\
\text { uses }\end{array}$ & $\begin{array}{l}\text { Degree of the mix of uses } \\
\text { Typology, scales }\end{array}$ \\
\hline & 1.2 Barrier-free design & $\begin{array}{l}\text { The inclusiveness of the built } \\
\text { environment }\end{array}$ & $\begin{array}{l}\text { The proportion of 'active' building frontage } \\
\text { Number of seating/resting places }\end{array}$ \\
\hline & 1.3 Street Design & $\begin{array}{l}\text { The degree of connectedness } \\
\text { and inclusivity enhance the } \\
\text { overall well-being of the } \\
\text { community }\end{array}$ & $\begin{array}{l}\text { Street networks, crowdedness } \\
\text { Number of junctions per street, nodes } \\
\text { Street noise }\end{array}$ \\
\hline & $\begin{array}{l}\text { 1.4 Natural } \\
\text { environment }\end{array}$ & $\begin{array}{l}\text { The comfort levels of the } \\
\text { environment affect the physical } \\
\text { and the psychological health of } \\
\text { elders }\end{array}$ & $\begin{array}{l}\text { The greenery (minimum of } 30 \% \text { ) } \\
\text { Number of shelters at public spaces } \\
\text { Outdoor air quality }\end{array}$ \\
\hline 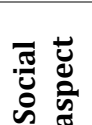 & 2.1 Neighbor support & $\begin{array}{l}\text { Interactions between the } \\
\text { neighbors }\end{array}$ & $\begin{array}{l}\text { Degree of the connections } \\
\text { Familiarity with the neighbors } \\
\text { Strength/support of the connections }\end{array}$ \\
\hline
\end{tabular}

Table 1 Domains of the built environment that affect elders

It is identified that the respondents must meet the participants' criteria of the study, and elders are occupied within the selected spatial scale. Therefore, the study approach deals with the characteristics of the neighborhood settlement at a meso-level as given in Table 1.

\section{Method}

Method of study is a hybrid approach that combines qualitative and quantitative methods as summarized in Figure 3. Thus, the methods are comprised of a questionnaire survey to acquire the age-related individual characteristics, an axial map analysis of the critical cases, and a frequency analysis of data to investigate the relationship of built environment attributes and the lifestyle of elders. 


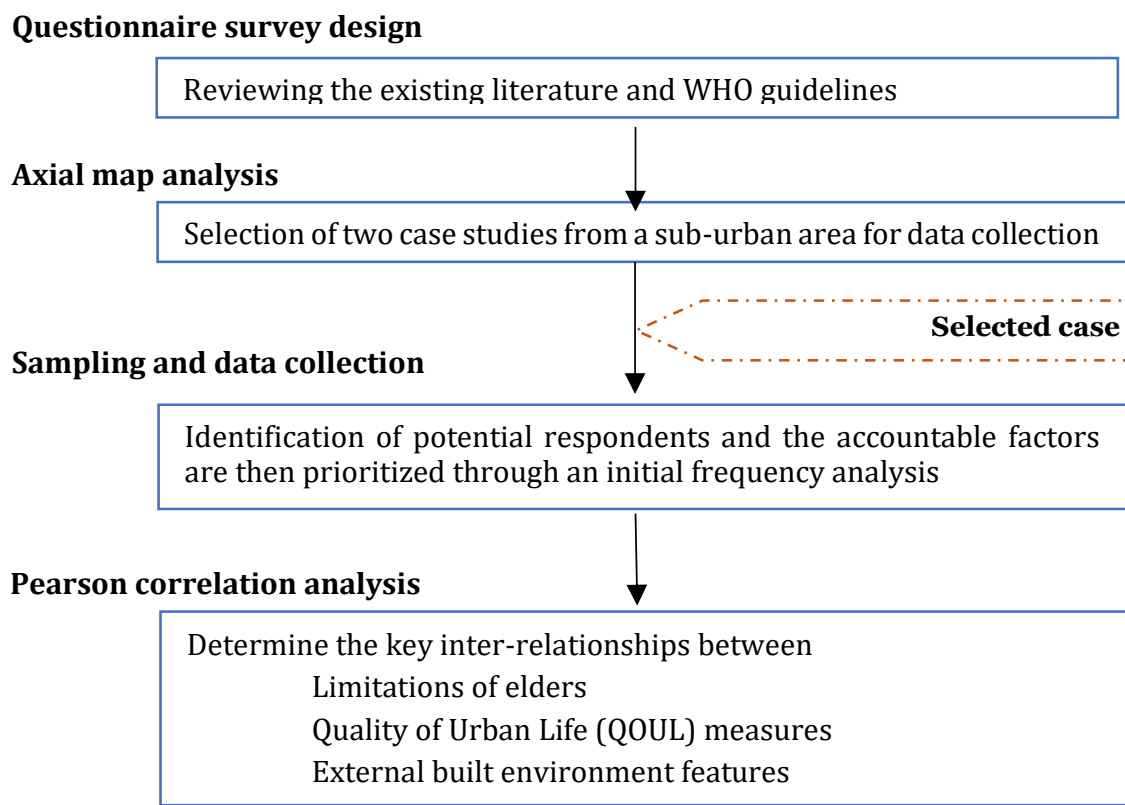

Figure 3 Research design

\section{Study design}

\subsection{QUESTIONNAIRE SURVEY}

Questionnaire survey was performed to acquire the age-related individual characteristics of the critical cases. Thus, was designed to recognize the prominent variables in the built environment affecting elders in urban areas. It is composed of two main sections namely; age-realted individual characteristics and the the built environment assessment. The summary details of each section are listed in Table 2 . The survey of 33 questions was formulated by reviewing the existing literature and renowned guidelines such as WHOQOLBREF (an abbreviated version of the WHOQOL-100).

The key questions expected to be addressed from the findings of the frequency analysis are which elements of the built environment restrict elders from their daily activities and the significant relationships between age-related characteristics and the built environment attributes:

- Which external built environment elements restrict elders from their daily activities?

- What are the links between age-related characteristics and the attributes of the built environment?

\begin{tabular}{ll}
\hline $\begin{array}{l}\text { Section I } \\
\text { General information of respondents }\end{array}$ & $\begin{array}{l}\text { Section II } \\
\text { Built environment assessment }\end{array}$ \\
\hline Personal characteristics & Pavements and curbs \\
Age & Walkways/roads \\
Gender & Street greenery \\
Civil status & Limited physical barriers \\
Income level & Public facilities \\
Education level & Provision for pedestrians \\
Whom they live with & Public transport \\
Type/extent of residency & Parking \\
Household size & Restricting traffic \\
\hline Age-related individual characteristics & Indoor-outdoor connections \\
Arthritis/ Joint stiffness & Location of health services \\
Fatigue & Recreation facilities \\
Back complaints & Clear signage \\
Injuries from Falls & Maintenance \\
Poor vision & Lighting after traffic \\
Poor hearing & \\
\hline
\end{tabular}

Table 2 Questionnaire framework summary 
Section one of the questionnaire contains the demographic and age-related characteristics of the respondents. The information included the age, gender, typology of the neighborhood, whom they live with, and the extent of residency. Section two focuses on the built environment attributes such as the physical barriers, accessibility to public facilities, and indoor-outdoor connections. Thus, deals with the assessment of the built environment attributes that affect the lifestyle of elders in high-density settlements. This was designed based on the literature review and the domains in the age-friendly checklist formulated by the WHO (2007). All selected respondents are elders in residential neighborhoods.

The feedback -from the two case studies was collected through a preliminary questionnaire and then through follow-up interviews. The questionnaire was administered to a randomly selected sample from the selected two case studies as the key component of the study. A count of 73 questionnaires was completed by the elders in total at a response rate of $91.25 \%$ percent. The respondents were interviewed for 10 mins with a paper-based questionnaire in the native language. The data collected is illustrated and then the quantifiable factors were identified based on frequency analysis.

Through the correlation tests performed for the quantifiable factors, the relationships were identified between age-related characteristics and the built environment attributes. Data were analyzed using statistical analysis of SPSS version 22 (version 22; IPM SPSS) for basic graphical analysis. The statistical analysis of Pearson's correlation was used at a significant level of 0.05 . Thus, finally aiding in establishing an appraisal from the most significant built environment attributes that effectively enhance the lifestyle of elders.

\subsection{AXIAL MAP ANALYSIS FRAMEWORK}

Subsequently, an axial map analysis was carried out using Depth map X software to identify the connectivity and integration for a better understanding of the neighborhood layout and to filter micro case study areas for in-depth analysis.

\subsection{SELECTED CASE STUDIES}

The aged population of Sri Lanka is unevenly distributed throughout the provinces while the majority of both the total population and the aged live in the Western province is 28.7 and 31\%, respectively. In considering this the selection of a case study was conducted within the Colombo city limits. Figure 4 shows the map of a case study location. The selection of the case study locations of Dehiwela-Mount Lavinia was centered on the distribution of population age, settlement types, and income levels. The areas meeting the above criteria were selected by overlaying an axial map using Depth map X software with a land-use map of the sub-urban area of Dehiwela-Mount Lavinia.

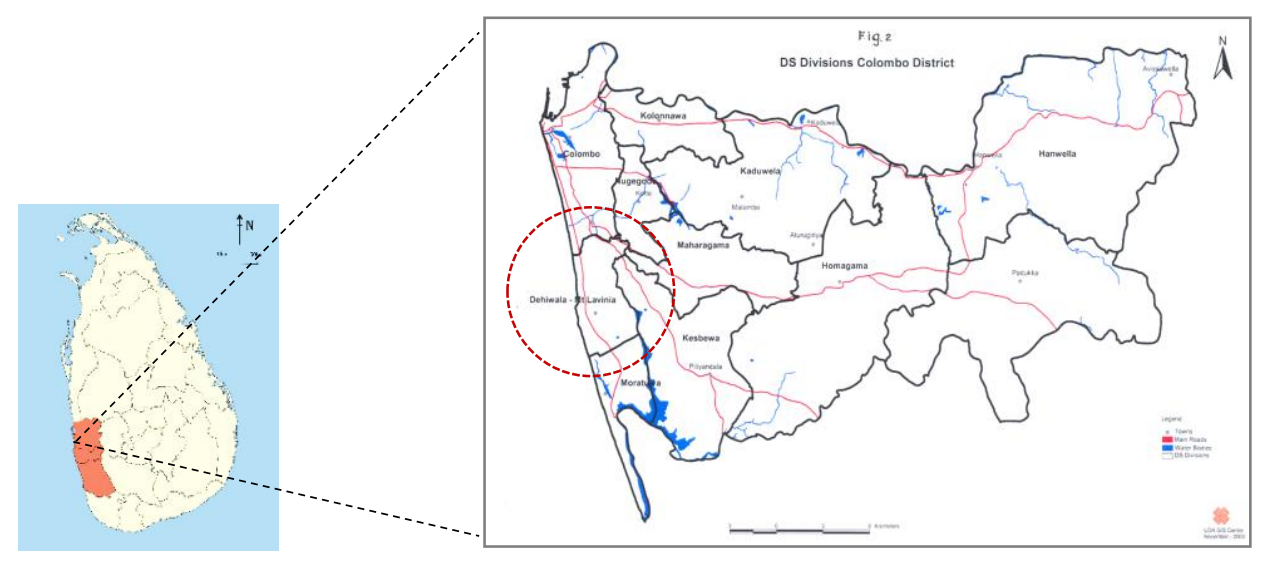

Figure 4 Dehiwala- Mount Lavinia Municipal council

(Source: The Urban Development Authority,2020)

This is the largest suburban area of Colombo with an extent of 2,127 hectares and consists of 28 Grama Niladari (GN) or regional divisions. This MC is located towards the south of Colombo Municipal council. Its boundaries of North, East, and South are Dehiwela canal, Weras ganga, and Borupana road, respectively. 
The built- up areas are classified as

- $\quad$ Residential
- Institutional
- $\quad$ Transport
- $\quad$ Civic
-

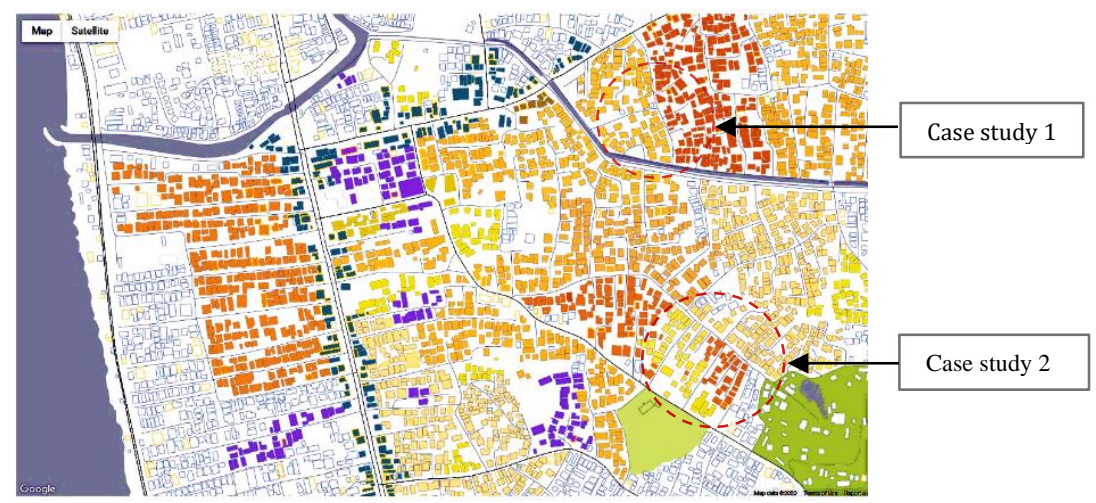

Figure 5 Micro-sites selection

The selected GN divisions of this study are as follows;

I. Galwala GN division (postal code 1130035)

II. Kalubowila GN division (postal code 1130025)

Figure 5 shows the composition of neighborhoods, and the characteristics of the high-density settlements are given in Table 3.

\begin{tabular}{ll}
\hline Case study 1- & Middle-income high-density settlement \\
\cline { 2 - 2 } $\begin{array}{l}\text { Galwala } \\
\text { GN division }\end{array}$ & The residential area is surrounded by the Anagarika \\
(n=37) & Dharmapala Mawatha and the Gal vihara road. \\
\cline { 2 - 2 } & $\begin{array}{l}\text { The majority of the built-up area is residential. } \\
\text { Mostly the typology of houses there are single and } \\
\text { double story houses }\end{array}$
\end{tabular}

\begin{tabular}{ll} 
Case study 2 & Low-income high-density settlement \\
\cline { 2 - 2 } $\begin{array}{l}\text { Kalubowila } \\
\text { GN division }\end{array}$ & $\begin{array}{l}\text { The residential area surrounded by the Nedimala } \\
\text { canal and the Hospital Road }\end{array}$ \\
\cline { 2 - 2 }$(\mathbf{n = 3 6 )}$ & $\begin{array}{l}\text { The majority of the built-up area is residential } \\
\text { Mostly the typology of houses there are single-story } \\
\text { row houses }\end{array}$
\end{tabular}
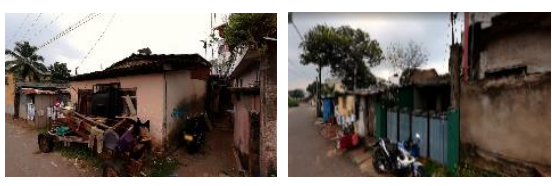

Table 3 Characteristics of high-density settlements of the selected case study GN divisions

\section{Results and Discussion}

The analysis of the findings explains the relationships between the built environment attributes and agerelated individual characteristics of elders. The study recognizes several outcomes in identifying the built environment response in enhancing the lifestyle of elders in urban areas. Based on the sampling and the data collected from the elders initially, the age-related individual characteristics and built environment attributes were categorized into primary and secondary forms.

\subsection{BUILT ENVIRONMENT ATTRIBUTES}

Findings of the initial frequency analysis as shown in Figure 6 shows that the physical attributes in the built environment related to residential surroundings such as condition of the pavements and curbs $(76 \%)$ and walkaways (73\%) significantly assist for fostering social activities such as visiting friends or shopping. Thus informs, these built environment attributes have the potential to reduce the impact of the age-related individual characteristics of elders, therefore enhancing the physical and emotional well-being measures.

The significance of the effect of each built environment attribute in daily activities of elders is identified using the frequency analysis of the statistical data obtained from the data collection whereas,

I. Primary category $51-100 \%$ frequency

II. Secondary category $1-50 \%$ frequency 


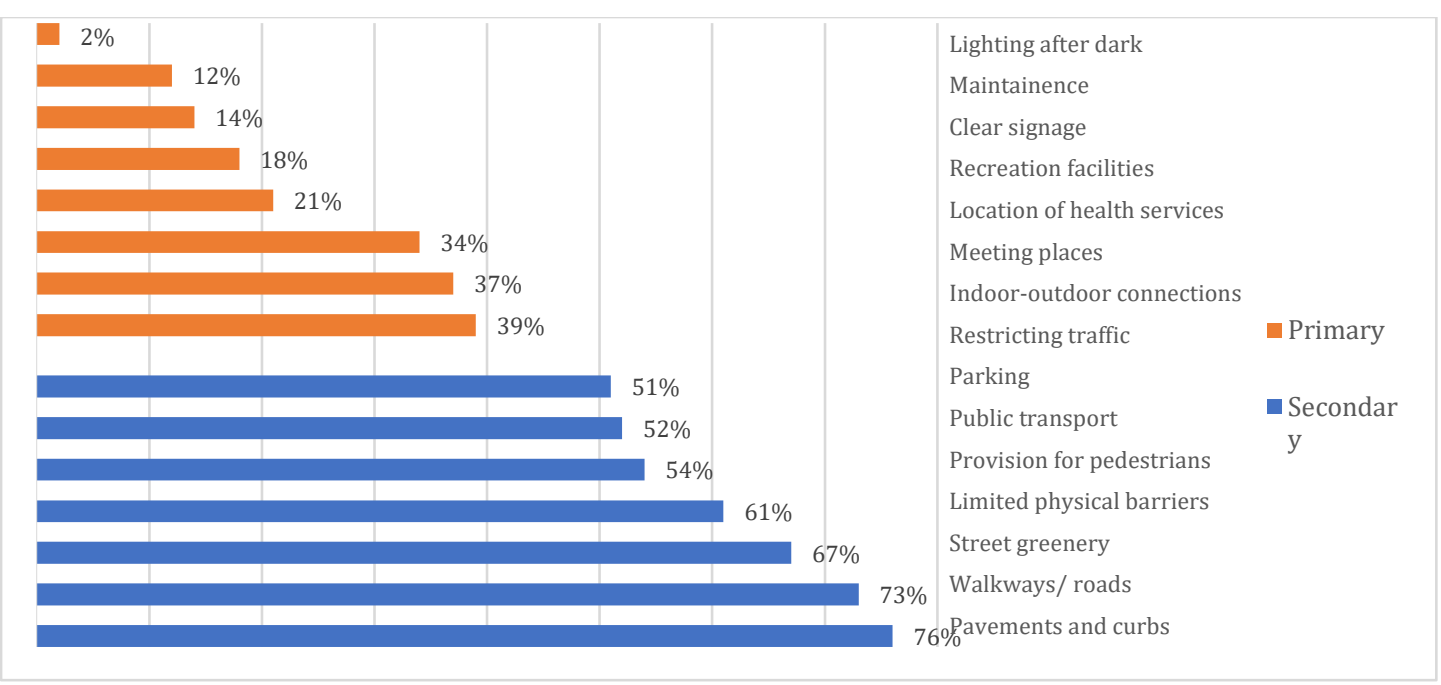

Figure 6 Built environment attributes

\subsection{AGE-RELATED CHARACTERISTICS}

The age-related characteristics with elders are of both physical and psychological aspect. The findings from the initial frequency analysis on such selected attributes illustrated in Figure 7 shows that most of the agerelated individual characteristics of elders are physical in nature and is associated with both sensory (vision, hearing) and movement (back complaints, joint stiffness, arthritis, fatigue).this was also highlighted by the department of census and statistics (2015). Furthermore, it reveals that the physical age-related conditions such as arthritis (72\%), poor vision (67\%) and dementia (67\%) psychologically significantly affect the daily activities of elders.

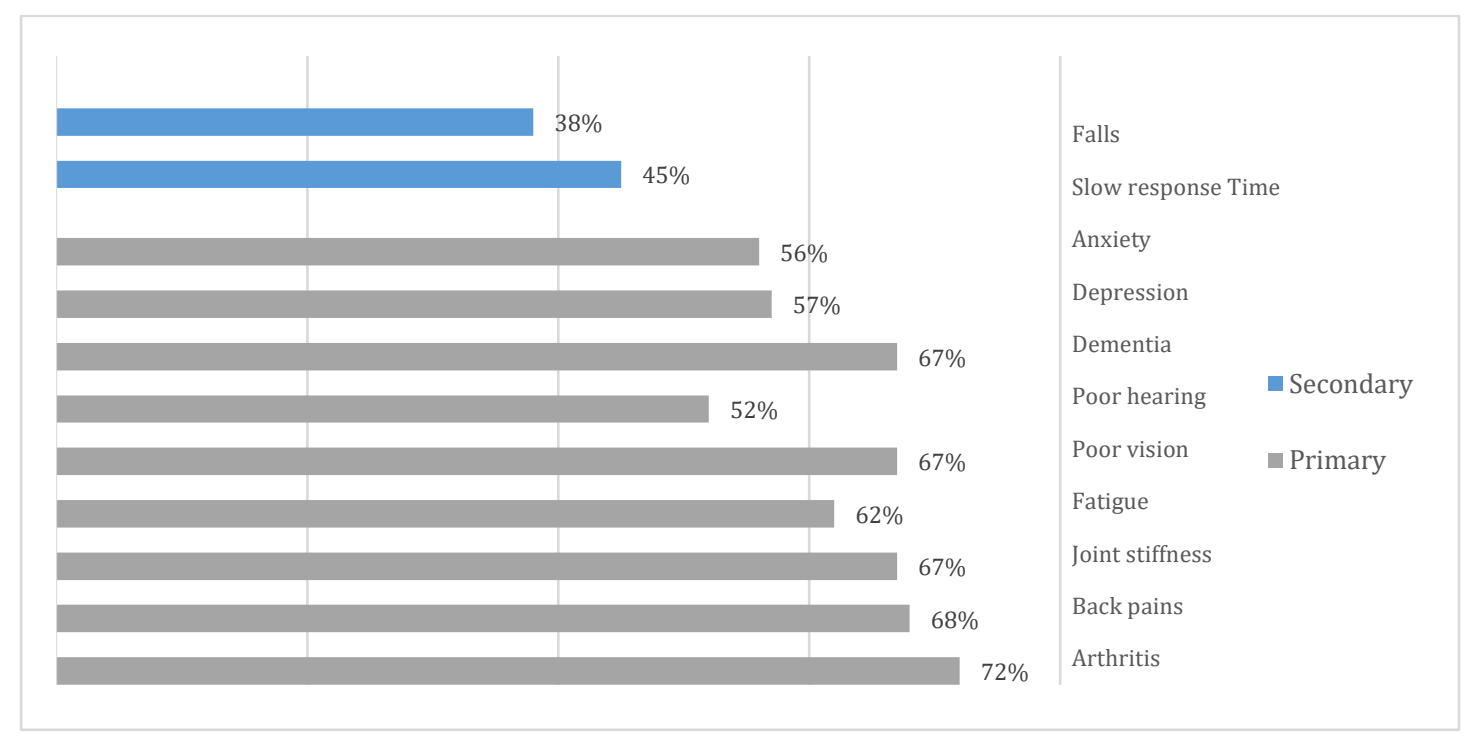

Figure 7 Age-related individual characteristics

It was also emphasized in the literature as well as through the questionnaire survey that in most cases the elders live with an age-related illness, therefore, give more prominence to health-related quality of life rather than the younger generations who are more concerned with the relationships, contentment, job, and income level (Browne et al., 1994) (Bowling, 1995). Therefore, it is vital in achieving a holistic approach to balance the different categories of end-users since there is no such thing as designing for a certain part of the community. Thus, to address this it is vital to identify the dependent variables in agerelated individual characteristics and the built environment attributes.

\subsection{COMPARISON BETWEEN THE VARIABLES IN THE SELECTED CASE STUDIES}

The findings suggest that the built environment attributes play a vital role in aiding the effect of age-related characteristics of elders thus, enhancing the lifestyle of elders in both the case studies. The results and the significant correlations are further discussed below in Table 4. 


\begin{tabular}{|c|c|}
\hline ase study $1(n=37)$ & Case study $2(n=36)$ \\
\hline $\begin{array}{l}\text { Indoor-outdoor connections are hindered by age- } \\
\text { related illnesses such as poor vision ( } \rho \text {-value .014) } \\
\text { and arthritis ( } \rho \text {-value .003). }\end{array}$ & $\begin{array}{l}\text { Improper pavements make it challenging for elders with } \\
\text { illnesses such as poor vision/hearing ( } \rho \text {-value } .000) \text {, } \\
\text { arthritis ( } \rho \text {-value .004), back pains ( } \rho \text {-value } .015) \text {, and } \\
\text { joint stiffness ( } \rho \text {-value .000) to perform their daily } \\
\text { activities. }\end{array}$ \\
\hline $\begin{array}{l}\text { Proper maintenance of the built environment is } \\
\text { required to overcome age-related illnesses faced by } \\
\text { elders such as poor vision ( } \rho \text {-value } .014) \text {, joint } \\
\text { stiffness ( } \rho \text {-value .006), and depression ( } \rho \text {-value } \\
.031) \text {. }\end{array}$ & $\begin{array}{l}\text { Due to the slow response time of some elders, it is ideal to } \\
\text { locate the health services and shops ( } \rho \text {-value.011) at } \\
\text { convenient locations. }\end{array}$ \\
\hline $\begin{array}{l}\text { Adequate accessibility is needed for elders suffering } \\
\text { from back pains ( } \rho \text {-value .029). }\end{array}$ & $\begin{array}{l}\text { Poor hearing is a key concern in creating crime-free } \\
\text { neighborhoods ( } \rho \text {-value .010) and activities ( } \rho \text {-value } \\
.000) \text {. }\end{array}$ \\
\hline $\begin{array}{l}\text { Location of health facilities and shops should be } \\
\text { located at nearby places to make it more reachable } \\
\text { for elders with arthritis ( } \rho \text {-value } .003) \text {, joint stiffness } \\
(\rho \text {-value } .008) \text {, etc. }\end{array}$ & $\begin{array}{l}\text { Elders suffering from physical impairments such as } \\
\text { arthritis ( } \rho \text {-value .001) and poor vision ( } \rho \text {-value .009) find } \\
\text { it challenging to maintain outdoor and indoor } \\
\text { connections. }\end{array}$ \\
\hline
\end{tabular}

Table 4 Age-related individual characteristics and built environment attributes

The analysis confirms that there are statistically significant relationships between age-related individual characteristics related to psychological aspects and the built environment attributes in the case of the middle-income settlement (Case study 1) as shown in Figure 8. Moreover, the relationships between the physical characteristics and the built environment affect both the case studies similarly.

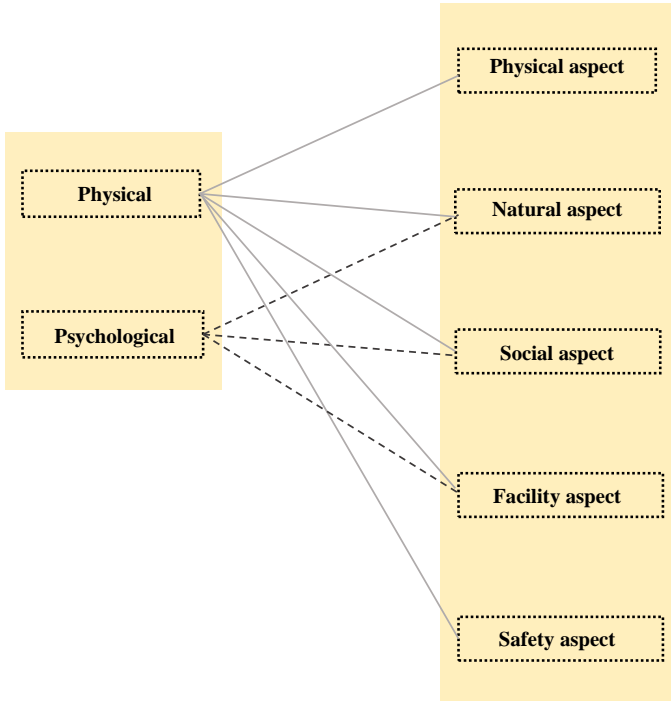

(a) Summary of Case study 1

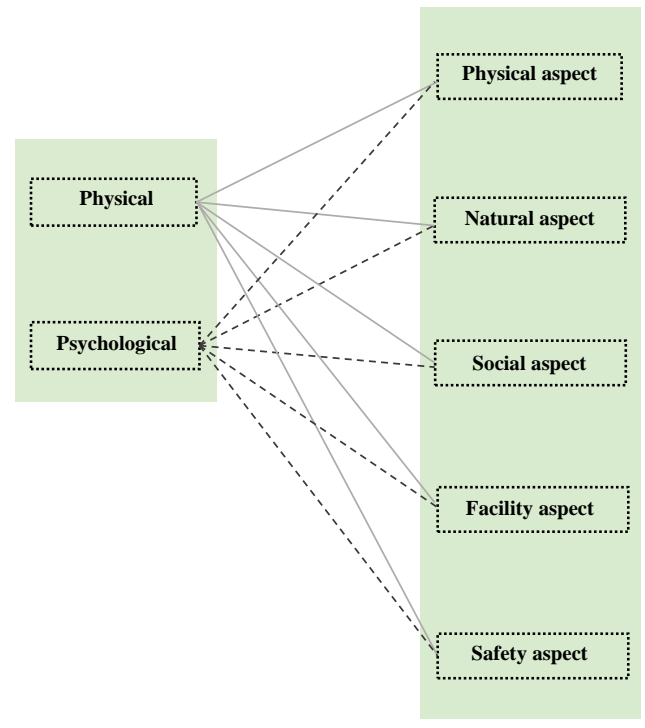

(b) Summary of Case study 2

Figure 8 Relationships between individual characteristics and built environment attributes (Summary)

The axial map analysis illustrated in Figure 9 identifies the connectivity and the integration of the neighborhood layout at different levels while highlighting the levels of improvement required at the micro case study areas to develop the appraisal. The well and poorly integrated locations of the neighborhood are highlighted in red and blue, respectively.

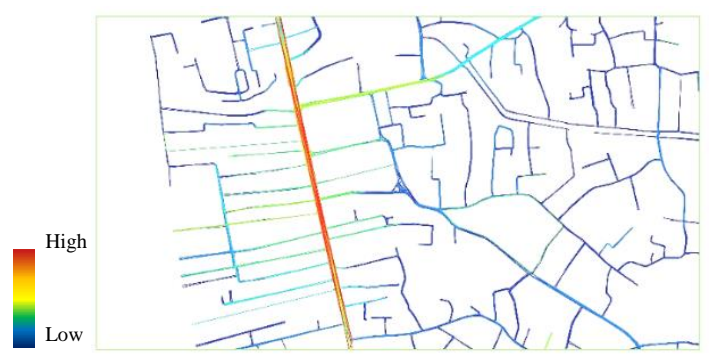

(a) Connectivity analysis, Depth map X

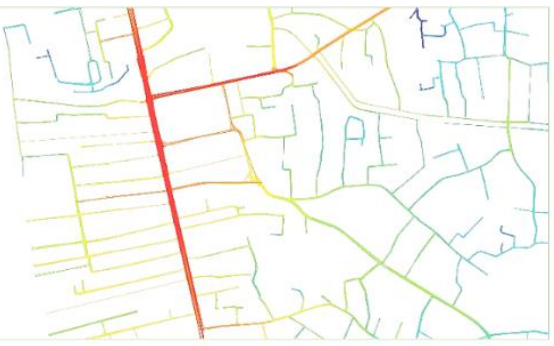

(b) Integration analysis, Depth map X

Figure 9 Axial map analysis for the selected study area 


\subsection{DEVELOPING THE APPRAISAL}

To develop an appraisal to identify the significance of the correlations between the built environment attributes that affect elders in their daily activities were rated based on a body ranking system corresponding to the relationship (low, medium, or high). Simultaneously, the absolute score is calculated based on the weighted importance and the relationship strength. Then, the contribution percentage of each built environment attribute is calculated which shows the hierarchy of the attributes summarized in Table 5 .

\begin{tabular}{llc}
\hline & Built environment attributes & Rating \\
\hline 1. & Pavements and curbs & 1 \\
\hline 2. & Lighting & 15 \\
\hline 3. & Walkways/roads & 11 \\
\hline 4. & Physical barriers & 12 \\
\hline 5. & Street greenery & 9 \\
\hline 6. & Activity & 4 \\
\hline 7. & Public amenities & 6 \\
\hline 8. & Recreation & 2 \\
\hline 9. & Accessibility & 5 \\
\hline 10. & Public Transport & 3 \\
\hline 11. & Restricting traffic & 8 \\
\hline 12. & Parking & 16 \\
\hline 13. & Maintenance & 7 \\
\hline 14. & Crime-free & 14 \\
\hline 15. & Pedestrian facilities & 13 \\
\hline 16. & Indoor-outdoor connections & 9 \\
\hline
\end{tabular}

Table 5 Rating of built environment attributes that support the needs of elders

Furthermore, the outcomes from the Quality Function Deployment (QFD) template were graphically represented in Figure 10.

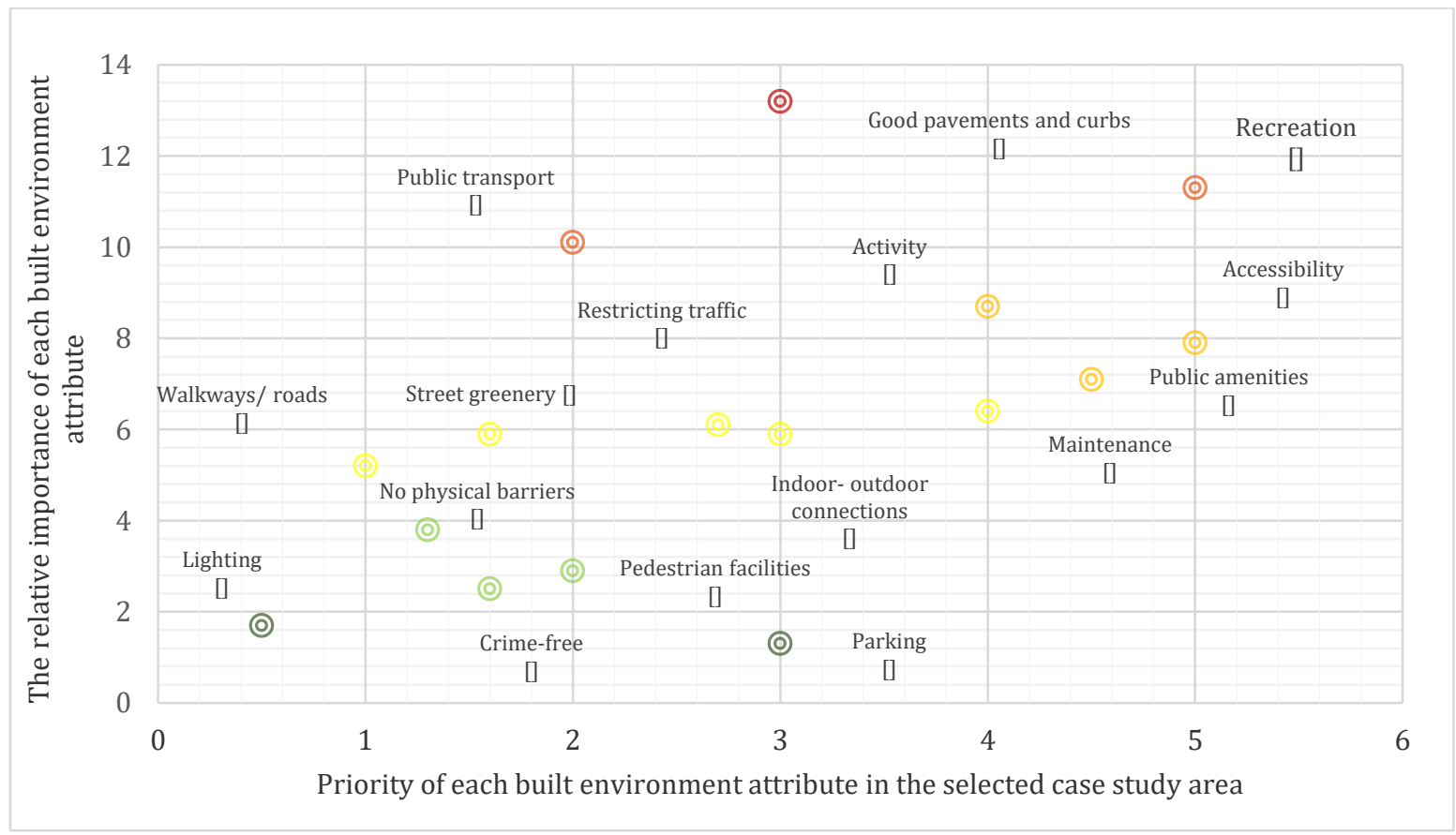

Figure 10 Priority levels of Built Environment attributes for the selected case study

Then the developed appraisal was validated where it was identified that it potentially has a simplified and practical application in deciding the key attributes in the built environment to enhance the 
quality of life of elders. vulnerable age groups like elders. Furthermore, as a starting point in future research on designing urban environments for aging well in community-based developing countries in the tropics like Sri Lanka.

\section{Conclusions}

The study recognizes several outcomes in identifying the built environment response in enhancing the quality of life of elders. Preliminarily, it was identified that there are significant interrelationships between the individual characteristics and the built environment attributes for elders emphasizing the need for a holistic approach to design decision-making. The recognized age-related individual characteristics of elders were mostly physical and are focused on mobility and sensory impairments. Subsequently, the Pearson correlation analysis which was carried out using the SPSS software for the selected case studies concluded that it is potentially possible to overcome physical age-related individual characteristics as well psychological conditions such as loneliness of elders through improved communal support and built environment attributes. This was further identified as crucial in terms of addressing the gaps in the existing guidelines provided by the governing bodies focusing on elders. The holistic approach of the proposed appraisal and how it has addressed the gaps in comparison to the existing guidelines.

Furthermore, the outcomes from the Quality Function Deployment (QFD) template it was highlighted that the state of street design (13.2\%), recreation (11.3\%), and transport (10.1\%) as the key built environment attributes that should be focused on in designing inclusive urban environments for elders. Thus, the template also facilitated focusing on fulfilling the specific needs of the stakeholder groups so that their needs are prioritized in the designing process. Finally, the study was able to conclude that it is potentially possible to apply the developed appraisal as a guideline for future urban design interventions while catering to vulnerable age groups like elders. Furthermore, as a starting point in future research on designing urban environments for aging well in community-based developing countries in the tropics like Sri Lanka.

\section{References}

Asian Development Bank (2019) Growing old before becoming rich: challenges of aging population in sri lanka, nature. Philippines. Doi: 10.1038/355392a0.

Bowling, A. (1995) 'What things are important in people's lives? A survey of the public's judgements to inform scales of health related quality of life', social science and medicine, 41(10), pp. 1447-1462. Doi: 10.1016/0277-9536(95)00113-l.

Browne, J. P. et al. (1994) 'Individual quality of life in the healthy elderly', quality of life research, 3(4), pp. 235-244. Doi: 10.1007/bf00434897.

Chaudhury, H. et al. (2016) 'Neighbourhood environment and physical activity in older adults', social science \& medicine, 149, pp. 104-113. Doi: 10.1016/j.socscimed.2015.12.011.

Helpage International (2015) Helpage international, global age watch index 2015: insight report. London. Loo, B.P.Y.; Mahendran, R.; Katagiri, K.; Lam, W. W. Y. (2017) 'Walking, neighbourhood environment and quality of life among older people', curr. Opin. Environ. Sustain., 25, pp. 8-13.

The Urban Development Authority (2020) Urban development plan for dehiwela-mount lavinia. Available at: https://www.uda.gov.lk/development-plans-reports.html?plan=4 (accessed: 20 december 2020).

Tönnies, F. (1957) Community \& society (gemeinschaft und gesellschaft). East lansing: michigan state university press.

UN Habitat (2014) Gender issue guide: gender responsive urban economy. Nairobi.

URPAS (2014) Urban and rural population by age and sex 1980-2015. Available at: http://esa.un.org/ unpd/popdev/urpas/urpas2014.aspx.

WHO (2007) Global age-friendly cities: a guide. Geneva, switzerland.

Youmans, E. G. (1977) 'Attitudes: young-old and old-old', gerontologist, 17(2), pp. 175-178. Doi: 10.1093/geront/17.2.175. 